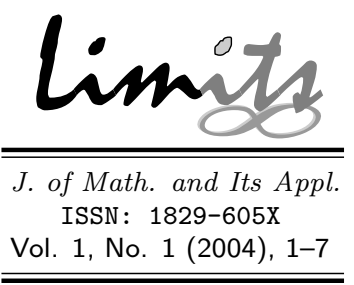

\title{
Desain Kontroler Tunggal Untuk Meredam Osilasi Multi Frekuensi Pada Sistem Skala Besar
}

\author{
Mardlijah \\ Jurusan Matematika \\ Institut Teknologi Sepuluh Nopember, Surabaya \\ mardlijah@matematika.its.ac.id \\ Adi Soeprijanto \\ Jurusan Teknik Elektro \\ Institut Teknologi Sepuluh Nopember, Surabaya \\ adisup@ee.its.ac.id
}

\begin{abstract}
Abstrak
Paper ini menjelaskan tahapan desain kontroler tunggal yang ditujukan untuk meredam lebih dari satu frekuensi osilasi yang terjadi pada suatu sistem skala besar termasuk metodametoda yang dikembangkan pada setiap tahapannya. Metoda ini dikembangkan terutama sangat berguna untuk desain kontroler pada sistem yang sangat besar serta memiliki multi frekuensi osilasi dan multi variabel state sebagai kandidat sinyal umpan balik. Pada tahap awal, dilakukan pemetaan frekuensi osilasi yang muncul untuk kemudian dipilih beberapa frekuensi sebagai target yang akan distabilkan. Selanjutnya, pengaruh masing-masing variabel state terhadap frekuensi target dianalisis dengan menggunakan faktor partisipasi. Variabel-variabel state yang dominan akan dipilih sebagai kandidat sinyal umpan balik. Jalur umpan balik didapat dengan menginjeksikan sinyal kontrol ke variabel state tertentu. Selanjutnya keefektifan jalur umpan balik dianalisis dengan konsep residu. Jalur umpan balik dengan nilai residu terbesar merupakan pilihan terbaik untuk meredam frekuensi target. Perhitungan kontroler dikembangkan berdasar kontrol robust dan akan diaplikasikan pada sistem riil ketenagalistrikan dalam level simulasi dengan Simulink-Matlab.
\end{abstract}

\section{Pendahuluan}

Dalam desain kontroler untuk suatu sistem kontrol otomatik tertentu, order sistem sangat mempengaruhi tingkat kesulitan desain. Sebagai contoh, pada sistem kecil dengan single input single output (SISO), pemilihan inputoutput kontroler tidak menjadi persoalan. Namun pada sistem-sistem besar, order matriks sistem bisa mencapai puluhan bahkan ratusan. Tipe-tipe frekuensi osilasi yang muncul juga beragam, berkisar antara $0,01 \mathrm{~Hz}$ - ribuan $\mathrm{Hz}$. Dalam kondisi semacam ini, sebelum sampai pada tahap desain kontroler, dilakukan berbagai analisis awal seperti pemetaan frekuensi osilasi, analisis sensitivitas antara variabel state dengan frekuensi osilasi dan penentuan jalur umpan balik efektif [1].

Dalam paper ini, pemetaan frekuensi osilasi dilakukan dengan menggunakan faktor partisipasi. Dengan menggunakan eigen value analysis dapat diketahui jumlah dan karakteristik masing-masing frekuensi (mode) yang muncul pada sistem. Kontribusi masing-masing variabel state terhadap mode tertentu dinyatakan sebagai faktor partisipasi variabel tersebut ter- 
hadap mode yang bersangkutan. Faktor partisipasi menunjukkan derajat sensitifitas antara variabel state tertentu dengan mode tertentu. Dengan demikian, variabel state dengan nilai faktor partisipasi yang tinggi merupakan kandidat umpan balik yang baik. Persoalannya kemudian hanya tergantung pada nilai observability-nya. Penentuan jalur umpan balik effektif ditentukan dengan memanfaatkan konsep residu. Nilai residu suatu jalur umpan balik sebanding dengan nilai observability variabel umpan balik dan nilai controlability tipe dan letak sinyal kontrol [2].

Pemanfaatan konsep residu dan faktor partisipasi untuk menentukan jalur umpan balik efektif kontroler telah diterapkan pada beberapa sistem ideal. Sayangnya, penerapan konsep ini untuk sistem skala besar masih sangat terbatas. Disamping itu, kontroler yang didesain hanya ditujukan untuk jenis osilasi (frekuensi) tertentu. Pada paper ini, konsep residu dan faktor partisipasi akan diterapkan untuk desain kontroler pada sistem tenaga listrik skala besar yaitu sistem interkoneksi Jawa-Bali $500 \mathrm{kV}$. Kontroler yang didesain ditujukan untuk meredam lebih dari satu jenis frekuensi osilasi sehingga diperlukan metoda khusus untuk penalaan parameter kontrolernya. Metoda penalaan yang dimaksud dikembangkan berdasar pada kontrol robust $[3]$.

\section{Desain Kontroler Pada Sistem Skala Besar}

Pada sistem skala besar, terdapat lebih dari satu kontroler untuk meredam berbagai osilasi yang terdapat dalam sistem. Gambar 1 menunjukkan interaksi antar berbagai kontroler $\left(H_{i}\right)$ pada suatu sistem. Idealnya, setiap kontroler bekerja secara independen (satu kontroler untuk meredam satu frekuensi) dan tidak saling memberikan pengaruh negatif. Pada paper ini, desain dan telaah dilakukan untuk satu kontroler yang mampu meredam beberapa frekuensi osilasi sekaligus dengan asumsi pengaruh kontroler lain diabaikan.

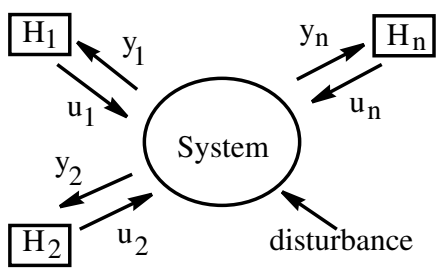

Gambar 1: Multikontroler pada Sistem Skala Besar

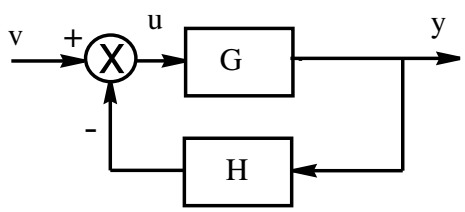

Gambar 2: Konfigurasi Umum Umpan Balik

Jika dilihat dari salah satu kontroler, konfigurasi sistem dapat digambarkan seperti pada Gambar 2. G merupakan model matematik sistem skala besar dilihat dari kontroler $H$. Model matematik ini dapat dinyatakan secara state space atau fungsi transfer Laplace. Nilai $v$ adalah nilai referensi yang dimanfaatkan untuk mengatur variabel kontrol. Tahapan desain kontroler tunggal dalam sistem skala besar:

i. Analisis kestabilan sistem melalui pemetaan frekuensi osilasi. Dalam tahap ini ditentukan pula frekuensi target (frekuensi-frekuensi kritis yang akan distabilkan).

ii. Pemilihan variabel dan jalur umpan balik untuk menjamin keefektifan kontroler.

iii. Reduksi model matematika sistem $G$ menjadi model nominal yang berisi hanya mode-mode osilasi yang akan distabilkan.

iv. Perhitungan kontroler dengan metode robust kontrol.

\section{Tahapan Desain}

\subsection{Pemetaan Frekuensi Osilasi dan Penentuan Frekuensi Target}

Untuk memetakan frekuensi osilasi, sistem skala besar direpresentasikan secara state space:

$$
\begin{aligned}
& \Delta \dot{x}=A \Delta x+B \Delta u \\
& \Delta y=C \Delta x+D \Delta u
\end{aligned}
$$




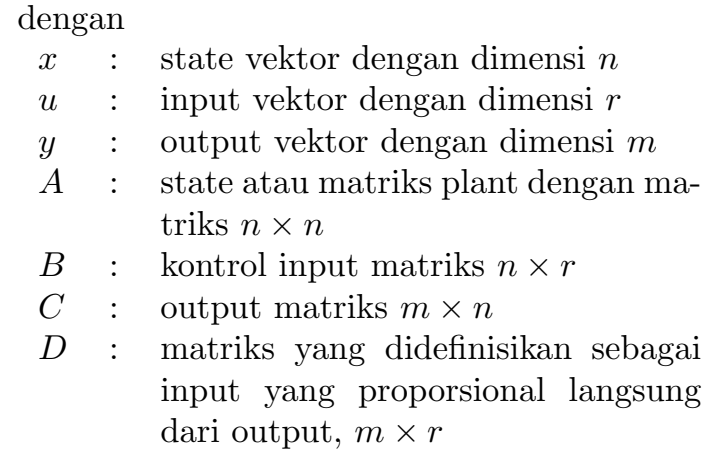

Nilai-nilai eigen matriks $A$ mengandung informasi nilai-nilai frekuensi osilasi sistem. Dengan menggunakan persamaan:

$$
(A-\lambda I) \phi=0
$$

dengan

$$
\begin{aligned}
& A \text { :matriks } n \times n \\
& \phi \text { :vektor } n \times 1, \phi \neq 0
\end{aligned}
$$

akan diperoleh nilai-nilai eigen $\lambda=\lambda_{1}, \lambda_{2}$, $\ldots, \lambda_{n}$. Komponen real nilai eigen menyatakan redaman sedangkan komponen imajiner menyatakan frekuensi osilasi. Nilai negatif pada bagian real menyatakan osilasi teredam (stabil) dan sebaliknya. Untuk nilai eigen pasangan kompleks:

$$
\lambda=\sigma \pm j \omega
$$

frekuensi osilasi dalam $\mathrm{Hz}$ adalah

$$
f=\frac{\omega}{2 \pi}
$$

dengan nilai rasio redaman

$$
\zeta=\frac{-\sigma}{\sqrt{\sigma^{2}+\omega^{2}}}
$$

Tipe frekuensi osilasi ditentukan berdasar pada variabel state dengan kontribusi dominan pada frekuensi tersebut. Untuk menghitung besar kontribusi setiap variabel terhadap setiap osilasi digunakan faktor partisipasi. Faktor partisipasi dari variabel state ke- $i$ terhadap mode ke- $k$ :

$$
P_{i k}=\Phi_{i k} \cdot \Psi_{i k}
$$

dengan $\Phi_{i k}$ dan $\Psi_{i k}$ berturut-turut menyatakan elemen dari eigen vektor kanan dan eigen vektor kiri matriks $A$. Eigen vektor kanan $(\Phi)$ dan eigen vektor kiri $(\Psi)$ didefinisikan :

$$
A \Phi=\Lambda \Phi, \quad \Psi=\Phi^{-1}
$$

dengan $\Lambda$ matriks diagonal dengan elemen semua nilai eigen $\lambda_{i}$.

Penentuan frekuensi target didasarkan pada nilai redaman setiap frekuensi dan tipe frekuensi. Frekuensi-frekuensi dengan nilai redaman sangat kecil (mendekati nol) dan memiliki tipe sejenis akan diambil sebagai target. Kesamaan tipe frekuensi target sangat penting karena berhubungan dengan penentuan variabel umpan balik [4].

\subsection{Pemilihan Jalur Umpan Balik}

Untuk meredam frekuensi-frekuensi target, jalur umpan balik ditentukan dengan nilai residu. Residu $R_{k}^{i j}$ merepresentasikan keefektifan jalur umpan balik ke- $i$ dan posisi masuk sinyal kontrol ke- $j$ untuk meredam mode (frekuensi) target ke- $k$. Secara matematik dapat dirumuskan sbb:

$$
R_{k}^{i j}=C_{i} \Phi_{k} \Psi_{k} B_{j}
$$

dengan

$R_{k}^{i j}$ : residu jalur umpan balik

$C_{i}$ : matriks output baris ke- $i$

$\Phi_{k}$ : kolom ke- $k$ dari vektor eigen kanan

$\Psi_{k}$ : baris ke- $k$ dari vektor eigen kiri

$B_{j}$ : matriks input kolom ke- $j$

Nilai residu yang tinggi menunjukkan tingkat keefektifan yang tinggi dalam meredam frekuensi target. Jika tipe frekuensi target sama, dimungkinkan untuk membuat jalur umpan balik SISO. Jika tidak, maka kontroler dapat berbentuk MIMO.

\subsection{Pembentukan Model Nominal}

Untuk menurunkan order kontroler yang akan di desain, order dari plant $G(s)$ direduksi menjadi $G_{r}(s)$. Secara matematik:

$$
G(s)=G_{r}(s)+G_{n}(s)
$$

dengan

$$
G_{r}(s)=\sum_{k \in T} \frac{\rho_{k}^{i j}}{s-\lambda_{k}}, \quad G_{n}(s)=\sum_{l \in T} \frac{\rho_{l}^{i j}}{s-\lambda_{l}}
$$

$G_{r}(s)$ merupakan model sistem reduksi yang hanya terdiri dari frekuensi-frekuensi target, 
sedangkan $G_{n}(s)$ merupakan model yang terdiri dari frekuensi-frekuensi non target. $T$, $\lambda_{k}, \rho_{k}^{i j}$ berturut-turut adalah domain frekuensi target, nilai eigen frekuensi target dan nilai keefektifan jalur umpan balik ij untuk mengontrol frekuensi target $k . \lambda_{l}$ dan $\rho_{l}^{i j}$ berturutturut merupakan nilai eigen frekuensi nontarget dan nilai keefektifan jalur umpan balik $i j$ untuk mengontrol frekuensi non-target $l$. Dalam desain kontroler, $G_{r}(s)$ akan dipakai sebagai plant nominal sedangkan $G_{n}(s)$ sebagai uncertainty.

\subsection{Perhitungan Kontroler Robust}

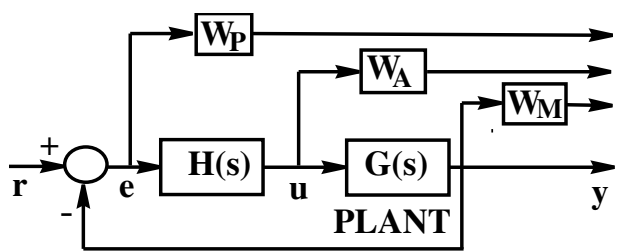

Gambar 3: Struktur Dasar Desain Kontroler Dengan Robust $H_{\infty}$

Model nominal yang diperoleh dalam tahap sebelumnya akan digunakan untuk desain kontroler menggunakan metode $H_{\infty}$. Gambar 3 menunjukkan struktur dasar desain. $W_{p}, W_{A}$ dan $W_{M}$ berturut-turut adalah weighting function yang dimanfaatkan untuk mengatasi noise, disturbance dan ketidakpastian model. Pencarian parameter kontroler $H(s)$ dilakukan dengan optimasi persamaan:

$$
\left\|\begin{array}{c}
W_{p}(s) S(s) \\
W_{A}(s) R(s) \\
W_{M}(s) T(s)
\end{array}\right\|_{\infty} \leq 1
$$

dengan

$$
\begin{aligned}
& S(s)=\left[1+G_{r}(s) H(s)\right]^{-1} \\
& R(s)=H(s) S(s) \\
& T(s)=1-S(s)=G_{r}(s) H(s) S(s)
\end{aligned}
$$

$S(s), R(s)$, dan $T(s)$ berturut-turut adalah fungsi transfer antara $r$ dengan $e, r$ dengan $u$, dan $r$ dengan $y$. Optimasi di atas telah mengandung syarat kestabilan internal [5].

\section{Implementasi}

\subsection{Deskripsi Plant dan Permodelan}

Metode yang dikembangkan akan diaplikasikan untuk desain kontroler pada sistem tenaga listrik guna meredam osilasi mekanik yang muncul. Letak kontroler yang didesain adalah pada generator yang dinilai effektif untuk tujuan peredaman [6]. Sistem tenaga listrik yang dipilih adalah sistem tenaga listrik $500 \mathrm{kV}$ Jawa Bali. Gambar sistem tenaga listrik 500 $\mathrm{kV}$ Jawa Bali beserta data jaringan dapat dilihat pada lampiran (Tabel 4). Generator dimodelkan sebagai two axis model, exciter dan governor sebagai sistem order satu [7].

\subsection{Spesifikasi Desain}

Pada riset ini, spesifikasi utama yang akan dicapai adalah nilai redaman dari frekuensifrekuensi mekanik berkisar 0,4-0,7.

\subsection{Hasil per Tahap}

Hasil pemetaan frekuensi osilasi plant terlihat pada Tabel 1. Pada tabel tersebut hanya ditampilkan sebagian saja dari keseluruhan frekuensi sistem. Terlihat bahwa frekuensifrekuensi dengan nomor mulai 29 sampai dengan 42 merupakan frekuensi-frekuensi kritis karena memiliki nilai redaman yang sangat rendah. Disini, hanya akan diambil dua frekuensi kritis sebagai frekuensi target yaitu frekuensi interarea mekanik dan frekuensi lokal mekanik. Dengan menggunakan faktor partisipasi dapat diketahui bahwa frekuensi nomor 31,32 adalah interarea mekanik. Untuk menentukan frekuensi lokal mekanik mana yang akan diambil sebagai frekuensi target, terlebih dahulu ditentukan jalur umpan balik (posisi) kontroler dengan konsep residu. Hasilnya terlihat pada Tabel 2 yang menunjukkan bahwa variabel kecepatan pada generator Cirata (generator 3) merupakan umpan balik yang paling efektif untuk meredam osilasi inter-area. Output kontroler akan dimasukkan kedalam rangkaian eksitasi generator cirata.

Dengan demikian frekuensi lokal mekanik yang diambil sebagai target adalah lokal mekanik di cirata. Dengan faktor partisipasi diketahui bahwa frekuensi lokal mekanik cirata adalah frekuensi no 37,38. Dengan demikian 
model reduksi yang akan dipakai untuk mendisain kontroler adalah mode 31, 32, 37 dan 38 . Dengan menggunakan metode yang diuraikan pada Sub-bab 3.4 dan dengan menggunakan weighting functions:

$$
\begin{aligned}
W_{M} & =\frac{0,2\left(s^{2}+101 s+100\right)}{s^{2}+25 s+100} \\
W_{P} & =\frac{10(s+300)}{s+10} \\
W_{A} & =\frac{0,1 s^{2}+100,001 s+1}{0,1 s^{2}+1,1 s+1}
\end{aligned}
$$

diperoleh kontroler dengan fungsi transfer:

$$
H(s)=\frac{0,05 s^{5}+0,46 s^{4}+1,82 s^{3}+2,61 s^{2}+1,11 s-0,12}{12,7 s^{5}+21,6 s^{4}+147 s^{3}+396 s^{2}+458 s+192}
$$

Setelah dipasang kontroler, nilai eigen untuk frekuensi 31, 32, 37 dan 38 disajikan dalam Tabel 3 (lihat Lampiran).

\subsection{Simulasi dan Analisis}

Gambar 4 dan Gambar 5 menunjukkan respon $\delta$ dan $\omega$ sebelum dan setelah pemasangan kontroler di Cirata terhadap gangguan step pada beban. Dari bentuk grafik osilasi, terlihat bahwa nilai osilasi redaman berkisar antara 0,5 - 0,7. Dengan demikian, kontroler yang didesain cukup efektif dalam meredam osilasi mekanik lokal dan inter-area.

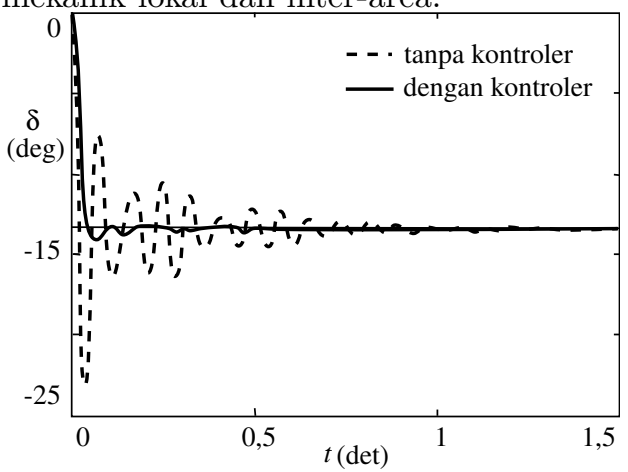

Gambar 4: Respon $\delta$ Cirata

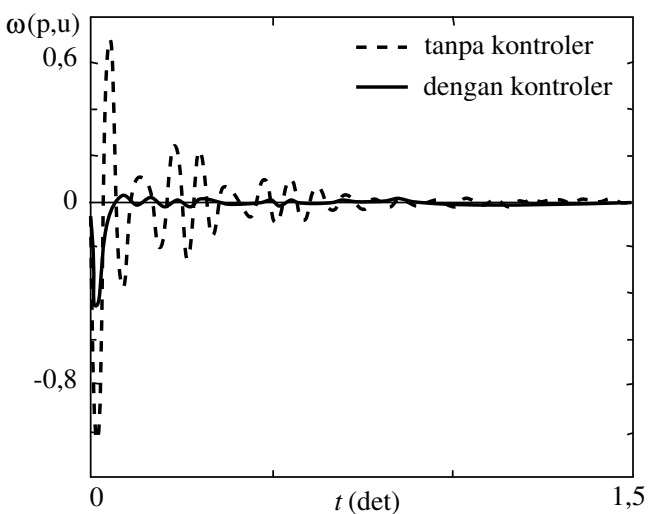

Gambar 5: Respon $\omega$ Cirata

Limits Journal of Mathematics and Its Applications, Volume 1, Number 1, May 2004

\section{Kesimpulan}

Dari hasil simulasi dan analisa dapat diambil beberapa kesimpulan:

a. Metoda yang dikembangkan dalam paper ini terbukti mampu menghasilkan kontroler yang efektif meredam beberapa osilasi frekuensi sekaligus.

b. Dengan metoda yang dikembangkan, order kontroler menjadi kecil sehingga mempermudah implementasi.

c. Pemasangan kontroler pada generator Cirata terbukti efektif meredam osilasi lokal dan inter-area mekanik dan dapat menaikkan nilai redaman sampai sekitar $0,5-0,7$.

\section{Daftar Pustaka}

[1] M. Klein, L.X. Lee, G.J. Rogers, S. Farrokhpay, N.J. Balu, " $H_{\infty}$ Damping Controller Design in Large Power Systems", IEEE Trans. on Power System, Vol. 10, No. 1, February 1995.

[2] P. Kundur, Power System Stability and Control, McGraw-Hill, Inc., 1994.

[3] K.A. Folly, A Study on the Design of Robust PSS Using H8 Control, Ph.D thesis, Hiroshima University, Feb, 1997.

[4] Adi Soeprijanto, N. Yorino, H. Sasaki, "A Method for Constructing Reduced Models Effective for Designing Coordinated $H_{\infty}$ PSS's", Proceedings of the 1999 ICEE, (1999) pp. 281-284.

[5] K.A. Folly, N.Yorino, H.Sasaki, "An Improved H8 PSS", Trans. of IEE Japan, Vol. 118-B, No. 6, June, 1998.

[6] Nelson Martin, Leonardo T.G. Lima, "Determination of Suitable Locations for Power System Stabilizers and SVC for Damping Electromechanical Oscillations in Large Scale Power Systems", IEEE Trans. on PS, Vol. 5, No. 4, November 1990, pp.14551469.

[7] P.M. Anderson, A.A. Fouad, Power System Stability and Control, Iowa State University Press, 1977. 


\section{Lampiran}

Tabel 1: Frekuensi Osilasi Plant

\begin{tabular}{|c|c|c|c|}
\hline Mode & Eigenvalues & $\begin{array}{c}\text { Damping } \\
\text { Ratio }\end{array}$ & $\begin{array}{c}\text { Frekuensi } \\
(\mathrm{Hz})\end{array}$ \\
\hline 8,9 & $-2.1770 \mathrm{e}+001+3.4672 \mathrm{e}+001 \mathrm{i}$ & $5.32 \mathrm{e}-01$ & $6.51 \mathrm{e}+00$ \\
10,11 & $-2.4880 \mathrm{e}+001+3.9902 \mathrm{e}+001 \mathrm{i}$ & $5.29 \mathrm{e}-01$ & $7.48 \mathrm{e}+00$ \\
12,13 & $-2.4467 \mathrm{e}+001+2.1540 \mathrm{e}+001 \mathrm{i}$ & $7.51 \mathrm{e}-01$ & $5.19 \mathrm{e}+00$ \\
29,30 & $-2.8391 \mathrm{e}-003+3.5819 \mathrm{e}-002 \mathrm{i}$ & $7.90 \mathrm{e}-02$ & $1.17 \mathrm{e}+00$ \\
31,32 & $-3.9415 \mathrm{e}-003+7.7270 \mathrm{e}-002 \mathrm{i}$ & $5.09 \mathrm{e}-02$ & $4.54 \mathrm{e}-01$ \\
33,34 & $-4.0392 \mathrm{e}-003+8.7422 \mathrm{e}-002 \mathrm{i}$ & $4.62 \mathrm{e}-02$ & $1.39 \mathrm{e}+00$ \\
35,36 & $-5.4216 \mathrm{e}-003+9.9603 \mathrm{e}-002 \mathrm{i}$ & $5.44 \mathrm{e}-02$ & $1.86 \mathrm{e}+00$ \\
37,38 & $-4.5695 \mathrm{e}-003+9.8397 \mathrm{e}-002 \mathrm{i}$ & $4.64 \mathrm{e}-02$ & $1.81 \mathrm{e}+00$ \\
39,40 & $-6.4803 \mathrm{e}-003+1.1640 \mathrm{e}-001 \mathrm{i}$ & $5.56 \mathrm{e}-02$ & $1.58 \mathrm{e}+00$ \\
41,42 & $-5.9740 \mathrm{e}-003+1.1416 \mathrm{e}-001 \mathrm{i}$ & $5.23 \mathrm{e}-02$ & $1.57 \mathrm{e}+00$ \\
\hline
\end{tabular}

Tabel 2: Residu Inter-area

\begin{tabular}{|c|ccccccc|}
\hline \multirow{2}{*}{$\begin{array}{c}\text { Var. } \\
\text { state }\end{array}$} & \multicolumn{7}{|c|}{ Tegangan Generator } \\
\cline { 2 - 8 } & Vt1 & Vt2 & Vt3 & Vt4 & Vt5 & Vt6 & Vt7 \\
\hline$\delta_{1}$ & $2.29 \mathrm{e}-03$ & $1.78 \mathrm{e}-03$ & $2.53 \mathrm{e}-02$ & $3.35 \mathrm{e}-03$ & $4.40 \mathrm{e}-04$ & $1.92 \mathrm{e}-04$ & $1.15 \mathrm{e}-04$ \\
$\omega_{1}$ & $1.76 \mathrm{e}-04$ & $1.37 \mathrm{e}-04$ & $1.95 \mathrm{e}-01$ & $2.58 \mathrm{e}-04$ & $3.39 \mathrm{e}-05$ & $1.48 \mathrm{e}-05$ & $8.83 \mathrm{e}-06$ \\
$\delta_{2}$ & $1.32 \mathrm{e}-03$ & $1.03 \mathrm{e}-03$ & $1.46 \mathrm{e}-02$ & $1.93 \mathrm{e}-03$ & $2.54 \mathrm{e}-04$ & $1.10 \mathrm{e}-04$ & $6.60 \mathrm{e}-05$ \\
$\omega_{2}$ & $1.02 \mathrm{e}-04$ & $7.90 \mathrm{e}-05$ & $1.12 \mathrm{e}-01$ & $1.49 \mathrm{e}-04$ & $1.95 \mathrm{e}-05$ & $8.50 \mathrm{e}-06$ & $5.09 \mathrm{e}-06$ \\
$\delta_{3}$ & $2.60 \mathrm{e}-03$ & $2.02 \mathrm{e}-03$ & $2.21 \mathrm{e}-02$ & $3.80 \mathrm{e}-03$ & $4.99 \mathrm{e}-04$ & $2.17 \mathrm{e}-04$ & $1.30 \mathrm{e}-04$ \\
$\omega_{3}$ & $1.99 \mathrm{e}-04$ & $1.56 \mathrm{e}-04$ & $2.87 \mathrm{e}-01$ & $2.93 \mathrm{e}-04$ & $3.84 \mathrm{e}-05$ & $1.67 \mathrm{e}-05$ & $1.01 \mathrm{e}-05$ \\
$\delta_{4}$ & $8.34 \mathrm{e}-04$ & $6.49 \mathrm{e}-04$ & $9.22 \mathrm{e}-02$ & $1.22 \mathrm{e}-03$ & $1.60 \mathrm{e}-04$ & $6.98 \mathrm{e}-05$ & $4.18 \mathrm{e}-05$ \\
$\omega_{4}$ & $6.42 \mathrm{e}-05$ & $4.99 \mathrm{e}-05$ & $7.10 \mathrm{e}-03$ & $9.41 \mathrm{e}-05$ & $1.26 \mathrm{e}-05$ & $5.38 \mathrm{e}-06$ & $3.22 \mathrm{e}-06$ \\
$\delta_{5}$ & $1.32 \mathrm{e}-04$ & $1.03 \mathrm{e}-04$ & $1.46 \mathrm{e}-02$ & $1.93 \mathrm{e}-04$ & $2.54 \mathrm{e}-05$ & $1.11 \mathrm{e}-05$ & $6.61 \mathrm{e}-06$ \\
$\omega_{5}$ & $1.02 \mathrm{e}-05$ & $7.91 \mathrm{e}-06$ & $1.12 \mathrm{e}-03$ & $1.49 \mathrm{e}-05$ & $1.96 \mathrm{e}-06$ & $8.51 \mathrm{e}-07$ & $5.09 \mathrm{e}-07$ \\
$\delta_{6}$ & $1.09 \mathrm{e}-04$ & $8.45 \mathrm{e}-05$ & $1.20 \mathrm{e}-02$ & $1.59 \mathrm{e}-04$ & $2.09 \mathrm{e}-05$ & $9.09 \mathrm{e}-06$ & $5.44 \mathrm{e}-06$ \\
$\omega_{6}$ & $8.37 \mathrm{e}-06$ & $6.51 \mathrm{e}-06$ & $9.25 \mathrm{e}-04$ & $1.23 \mathrm{e}-05$ & $1.61 \mathrm{e}-06$ & $7.00 \mathrm{e}-07$ & $4.19 \mathrm{e}-07$ \\
$\delta_{7}$ & $5.51 \mathrm{e}-05$ & $4.28 \mathrm{e}-05$ & $6.10 \mathrm{e}-03$ & $8.07 \mathrm{e}-05$ & $1.06 \mathrm{e}-05$ & $4.61 \mathrm{e}-06$ & $2.76 \mathrm{e}-06$ \\
$\omega_{7}$ & $4.24 \mathrm{e}-06$ & $3.30 \mathrm{e}-06$ & $4.69 \mathrm{e}-04$ & $6.21 \mathrm{e}-06$ & $8.16 \mathrm{e}-07$ & $3.55 \mathrm{e}-07$ & $2.12 \mathrm{e}-07$ \\
\hline
\end{tabular}

Tabel 3: Nilai-nilai Eigen dengan Kontroler

\begin{tabular}{|c|c|c|c|}
\hline Mode & Eigenvalues & Damping Ratio & Frekuensi $(\mathrm{Hz})$ \\
\hline 31,32 & $-5.3443 \mathrm{e}-002+5.3659 \mathrm{e}-002 \mathrm{i}$ & $7.06 \mathrm{E}-01$ & $1.20 \mathrm{E}-02$ \\
37,38 & $-6.2890 \mathrm{e}-00+9,0896 \mathrm{e}-00 \mathrm{i}$ & $5.69 \mathrm{E}-01$ & $1.76 \mathrm{E}+00$ \\
\hline
\end{tabular}


Tabel 4: Data Saluran Transmisi 500 kV Jawa-Bali

\begin{tabular}{|c|c|c|c|c|}
\hline No & Saluran & $Z($ Ohm $/ \mathrm{km} / \mathrm{phasa})$ & $C(\mathrm{mF} / \mathrm{km})$ & Jarak $(\mathrm{km})$ \\
\hline 1 & Suralaya - Gandul & $0.02+\mathrm{j} 0.2$ & 0.01283 & 111.00 \\
2 & Suralaya - Cilegon & $0.02+\mathrm{j} 0.2$ & 0.01289 & 12.48 \\
3 & Cilegon - Cibinong & $0.02+\mathrm{j} 0.2$ & 0.01283 & 116.00 \\
4 & Gandul - Cibinong & $0.02+\mathrm{j} 0.2$ & 0.01283 & 21.30 \\
5 & Gandul - Kembangan & $0.02+\mathrm{j} 0.2$ & 0.01289 & 31.90 \\
6 & Cibinong - Saguling & $0.02+\mathrm{j} 0.2$ & 0.01283 & 80.30 \\
7 & Cibinong - Bekasi & $0.02+\mathrm{j} 0.2$ & 0.01283 & 37.92 \\
8 & Cibinong - Cawang & $0.02+\mathrm{j} 0.2$ & 0.01283 & 57.00 \\
9 & Cawang - Bekasi & $0.02+\mathrm{j} 0.2$ & 0.01277 & 18.00 \\
10 & Muara Tawar - Cibatu & $0.02+\mathrm{j} 0.2$ & 0.01283 & 55.00 \\
11 & Cibatu - Cirata & $0.02+\mathrm{j} 0.2$ & 0.01283 & 44.56 \\
12 & Cirata - Saguling & $0.02+\mathrm{j} 0.2$ & 0.01289 & 25.10 \\
13 & Saguling - Bandung Sel. & $0.02+\mathrm{j} 0.2$ & 0.01283 & 37.43 \\
14 & Bandung Sel. - Ungaran & $0.02+\mathrm{j} 0.2$ & 0.01283 & 342.80 \\
15 & Bandung Sel. - Maduracan & $0.02+\mathrm{j} 0.2$ & 0.01283 & 130.00 \\
16 & Maduracan - Ungaran & $0.02+\mathrm{j} 0.2$ & 0.01283 & 228.68 \\
17 & Ungaran - Krian & $0.02+\mathrm{j} 0.2$ & 0.01283 & 251.00 \\
18 & Ungaran - Pedan & $0.02+\mathrm{j} 0.2$ & 0.01277 & 75.00 \\
19 & Krian - Grati & $0.02+\mathrm{j} 0.2$ & 0.01289 & 74.00 \\
20 & Krian - Gresik & $0.02+\mathrm{j} 0.2$ & 0.01277 & 22.20 \\
21 & Grati - Paiton & $0.02+\mathrm{j} 0.2$ & 0.01289 & 74.00 \\
& Paiton - Pedan & $0.02+\mathrm{j} 0.2$ & 0.01277 & 410.00 \\
\hline
\end{tabular}

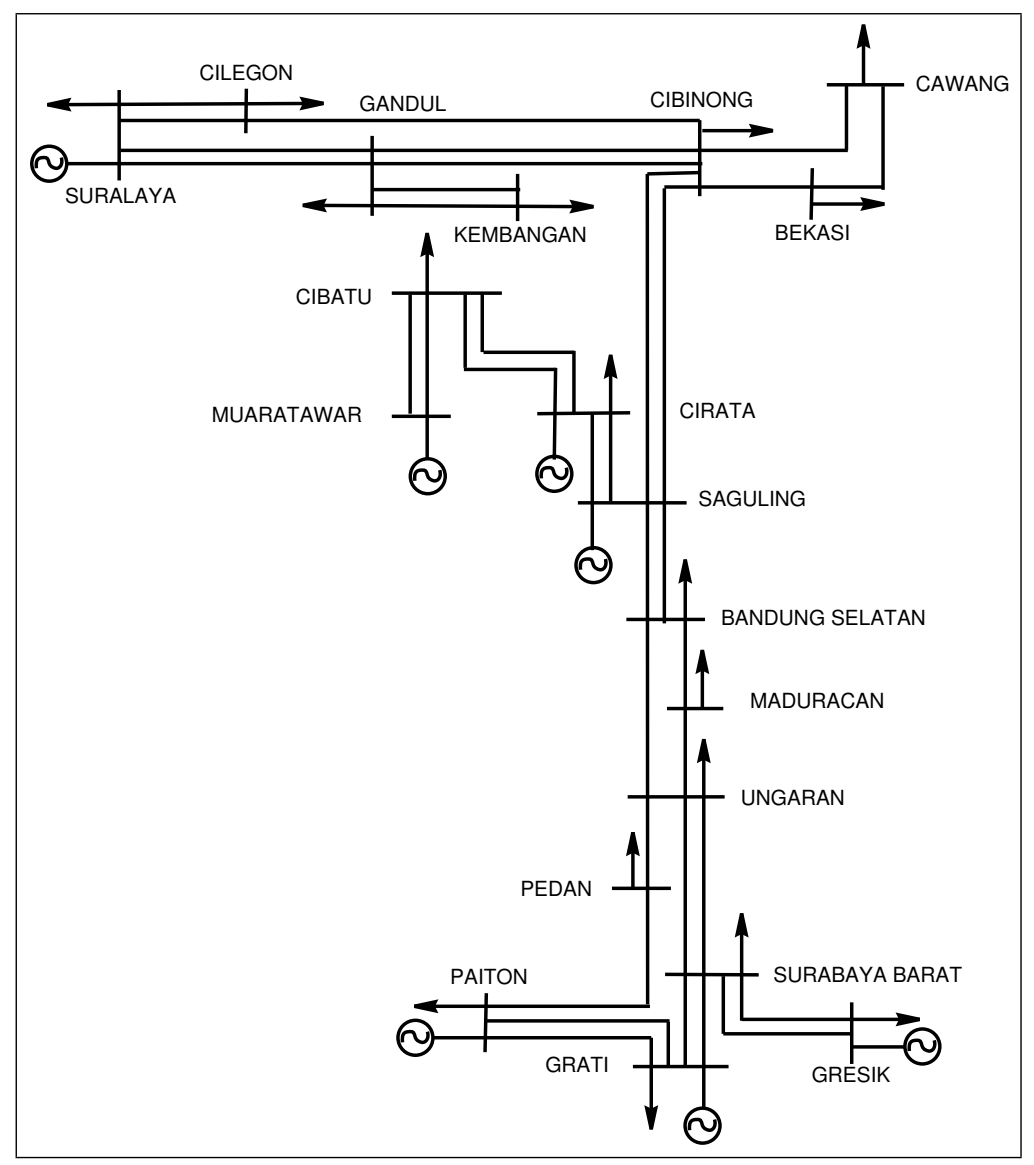

Gambar 6: Sistem Transmisi 500 kV Jawa Bali 